\title{
Does Delayed Testing of Urea Breath Test Samples Effect Results?
}

\author{
Michael Bruce $^{\mathrm{a}} \quad$ Alan Parkinson ${ }^{\mathrm{a}}$ Brad Gessner ${ }^{\mathrm{b}}$ \\ ${ }^{a}$ Arctic Investigations Program, Centers for Disease Control and Prevention, and ${ }^{b}$ Alaska Division of \\ Public Health, Section of Epidemiology, Anchorage, Alaska
}

In a randomized treatment trial for $\mathrm{He}$ licobacter pylori infection among 690 children in rural Alaska, 36 urea breath test (UBT) samples were lost in the mail. We recovered the samples 9-10 days later and tested them using the standard method (test session 1). Specimens were collected during the Fall season in Alaska during which the average temperature in the region was $44^{\circ} \mathrm{F}$ (range 35-53) and were transported in uninsulated cardboard boxes and flown as air cargo. Conditions under which the lost bags were stored are not known. The manufacturer of the UBT kits (Meretek, Lafayette, Colo., USA) recommends testing of breath test samples within 7 days of specimen collection to ensure a valid test result. Therefore, this set of test results was deemed questionable and all 36 participants were retested using the UBT. We compared the results of UBT testing from test session 1 with UBT samples collected 15 days later on the same 36 children and tested within 3 days of sample collection (test session 2). Testing was performed according to the manufacturer's specifications with a positive test based on a urea hydrolysis rate $>10$ from the delta over baseline for ${ }^{13} \mathrm{CO}_{2}$ after adjusting for weight, height, and gender. Among the 36 participants, 19 (53\%) were female, median age was 10.5 years (range 7.9-12.8 years). Test session 1 (median of 9 days between breath test collection and testing) revealed 19 positive and $17 \mathrm{H}$. pylori-negative samples. Test session 2 (median of 2 days between breath test collection and testing) revealed 20 positive and 16 negative tests. Test results between the two sample sets were concordant for all but one person $(97 \%$ of all tests) $($ Kappa $=0.94)$. A secondary measure of UBT results - the delta over baseline ${ }^{13} \mathrm{CO}_{2}$ concentration - gave identical results. The participant with discordant results tested negative in test session 1 but positive in test session 2 (UHR 0.8 and 31.3 , respectively). This could have occurred due to a false-negative result from test session 1, a false-positive result from test session 2 or acquisition of infection in the 15-day period between sample collections. Our data demonstrate that UBT results are not substantially changed even when testing is delayed for up to 9-10 days. This is particularly important for researchers working in remote regions where it may be difficult to test samples in a timely manner. Further studies are needed comparing longer durations between collection and testing and evaluating the effect of prolonged exposure to both heat and cold.

\section{KARGER}

Fax +4161306 1234 E-Mail karger@karger.ch www.karger.com www.karger.com/dig
Michael Bruce, MD

Centers for Disease Control and Prevention

National Center for Infectious Diseases, Arctic Investigations Program

4055 Tudor Centre Drive, Anchorage, AK 99508 (USA)

E-Mail zwa8@cdc.gov 